\title{
Study on Chinese-English Translation Strategies of the Culture of The Virtue and Filial Piety of Liangzhou
}

\author{
Zhang Fumin \\ College of Foreign Languages and Literature, Hexi University, Zhangye, Gansu 734000
}

Keywords: The Virtue and Filial Piety of Liangzhou; culture inheritance; translation strategies

\begin{abstract}
The Virtue and Filial Piety of Liangzhou is not only an art form for people especially the blind playing the music instrument Sanxian to sing the songs expressing their ideas, feeling, expectations as to people's behavior of speech and action to older people, also an important form of culture which has been inherited from generation to generation for about 2000 or 3000 years to call on young generation to be self-cultivated to care for the old generation and other people through obedience, careful and humble speech and action behavior reflected by themselves on a daily basis in family and society. As an important art and culture form, of course, The Virtue and Filial Piety of Liangzhou has powerful effect to cultivate people to pursue the virtue and standardize their daily behavior admired and implemented by the descendants of Yang and Huang. And the translation of such culture could enlarge its effect, attract more people to care for and inherit it. This paper, based on translation theory, culture inheritance theory, culture goingout theory and comprehension of the materials reflecting the culture of The Virtue and Filial Piety of Liangzhou, explores the translation strategies of such culture from Chinese to English. Research shows that translation of the culture of The Virtue and Filial Piety of Liangzhou from Chinese to English should follow at least nine strategies, and they are translator first, flexible utilization of both foreignization and domestication, translation alteration, adoption of register, human translation, deep translation, functionality + loyalty and scientific administration of translation behavior. And comprehensive utilization of the strategies could provide necessary safeguards for its translation and guarantee the quality of its target text which will be accepted and appreciated by people who use English.
\end{abstract}

\section{The Culture of The Virtue and Filial Piety of Liangzhou}

Wuwei is one of the five prefecture cities in Hexi Corridor in Gansu Province, and Liangzhou is the name for the Wuwei prefecture city in ancient times. During the year 104-88 BC, emperor Hanwu of the Western Han Dynasty established Four Prefectures in Hexi Corridor, and Liangzhou was one of them. The Virtue and Filial Piety of Liangzhou is originally an art form to express local people's ideas and thoughts as to the issue of Virtue and Filial Piety, and it used to be performed by the blinds playing the Chinese instrument Sanxian. Of course, the culture of The Virtue and Filial Piety is one of the local culture phenomena scattered and disseminated in Liangzhou prefecture even Hexi corridor area. As to the definition of culture, Krober \& Kluckhohn (1952) claim:

Culture consists of patterns, explicit and implicit, of and for behavior acquired and transmitted by symbols, constituting the distinctive achievements of human groups, including their embodiments in artifacts; the essential core of culture consists of traditional (i.e., historically derived and selected) ideas and especially their attached values; culture system may, on the one hand, be considered as products of action, on the other as conditioning influences upon further action.( Krober \& Kluckhohn 1952: 357)

And according to what the young scholar in Northwest Normal University Shan Lanjing (2012) advances,

Culture is the sum total of man's knowledge of the material culture and spiritual culture created by human beings in the process of transforming nature and society.......In general, culture mainly refers to the Psychoproductive capacity and intellectual products, including such part of the ideology as the Philosophy and social science, literature and art, the news media, cultural undertakings and cultural industries, the thought and the world outlook, the outlook on life, values, etc, also including science and technology, not part of the ideology of language and words, etc. ( Shan Lanjing 2012: 75-76)

Given the above, it's easily found that The Virtue and Filial Piety of Liangzhou is not only an art form for people especially the blind, also an important form of culture derived and inherited from generation to generation. Nowadays, The Virtue and Filial Piety of Liangzhou has been included in 
the national intangible cultural heritage of the People's Republic of China.

\section{Research Status}

In a way, Virtue and Filial Piety is a kind of traditional virtue of people, also a grace and good social behavior of people, which originally resulted from people's longings for harmonious family relationship in ancient times. People in ancient times wished the younger generation and the young would respect and be obedient to their elder member of a family and older people in society, and on the other hand support their directly-related members of their family whom were old and unable to support themselves under whatever conditions they were. This hope was also for the daughter-in-laws and the son-in-laws. This concept of family rules and orders were greatly in accordance with the Way of Confucius. Hence, it's gradually accepted by the people, officials and governments in ancient times. Based on the above reasons, Virtue and Filial Piety were urged to implement by people in societies in China. Nowadays, to maintain a good balance of family, Virtue and Filial Piety has been arousing more and more attention at home and abroad for its powerful effect to build a more harmonious society for the sake of the basic identity that family's the basic unit of a society. Many scholars at home and abroad are interested in it and its studies.

\subsection{Research Status Abroad}

Many foreign scholars compose articles and books to express their ideas as to the issue of Virtue and Filial Piety, but their views on this issue could roughly be divided into the following ones:

(1) Claims of family ethics. According to what they advocate in their articles, it's easily found that Lee Chung-Duk and Kim II-Myung etc., and Willian Sin as well hold such views. For example, Lee Chung-Duk and Kim II-Myung etc. (1998: 73-74) claims,

During the period of 1950s and 1960s extreme changes in political, economic, social and cultural environments had a great influence on family ethics.......The parents believe that the best filial piety is making good lives of their children’s own, which is somewhat different from the traditional filial piety norm.

And William Sin (2013:90) advocates,

As the virtue of filial piety plays a central role in the ethics of Confucianism, adult children will face stringent demands while giving care to their chronically ill parents.

(2) Claims of responsibility for older people. The scholars who hold such views include Joanna Afek, Dorota Kpupa etc. and Daniel W.L.Lai and Louise Edwards. In his article, Louise Edwards (2010) says,

This article traces the transformations of her(Hua Mulan) story from its inception in the Northern Wei ballad through to the 2010 cinema versions in order to trace the evolution of gendered forms of loyalty, patriotism, virtue and filial piety. (Louise Edwards 2010: 175)

Whatever Louise Edwards claims, Hua Mulan replacing her father to be the soldier and then general reflects her sincere care for her father even if she had brothers. Therefore, judging from Louise Edwards this article, his thoughts on the Virtue and Filial Piety belongs to this type. So is Daniel W.L.Lai(2013:290)'s view on it. As can be seen in his article Support and Care for Aging Chinese: A Comparison of Guangzhou, Hong Kong and Taipei,

As the traditional virtue, filial piety is highly regarded in the Chinese culture. It defines how elders should be respected and taken care of by the younger generations.

(3) Claims of Self-cultivation. As can be seen from his paper published, Katarzyna Pejda(2016:91) exactly hold this claim. He advocates,

The following paper presents Confucius' view on self-cultivation. The paper also contains analysis of two concepts: $d e-$ virtue and Xiao-filial Piety.......De is inborn, given by tian (heaven) whilst xiao, obedience towards parents and relatives, is acquired by proper education.

\subsection{Research Status in China}

Compared to foreign scholars, in my opinion, Chinese scholars have full and deep comprehension of The Virtue and Filial Piety of Liangzhou. However, their views could be roughly divided into these ones:

(1) Theory of Promotion and Development. Xi Jinpin, General Secretary of CPC, advocates in the Reports of the 19th National Congress of the Communist Party of China,

We will launch a civic morality campaign to raise public ethical standards, and enhance work ethics, family virtues, and 
personal integrity. We will encourage our people to strive for excellence and to develop stronger virtues, respect the elderly, love families, and be loyalty to the country and the people. (Xi Jinpin 2017:59)

(2) Theory of Folk Art. According to what they express in their published articles and papers, Men Wanpen \& Ma Nin and Zhao Yin think of The Virtue and Filial Piety of Liangzhou as the form of Folk Art.

(3) Theory of Folk Cultural Heritage. Li Guishen, Huo Zhijun, and Xue Mo's articles show that The Virtue and Filial Piety of Liangzhou is one of the folk cultural heritages.

However, though many young scholars put so much on the translation studies and several teachers (including Zhang Fumin, Li Yaqi, Miao Lijun, Li Yuting, Li Jianxin and Dong Jiali) in Hexi University have been engaging in the translation of Hexi Culture, in fact no research paper which embodies and reflects the translation of The Culture of The Virtue and Filial Piety of Liangzhou can be found anywhere. Therefore, author of this paper tries to explore the Translation Strategies of this culture.

\section{Theoretical Foundation of Research}

\subsection{Culture Inheritance}

It's commonly shared that culture inheritance not only contribute to the further development of the culture itself, also give priority to future generation's appreciation of the culture itself. On the other hand, without the culture inheritance, the culture itself could not survive in the world. Therefore, the culture of The Virtue and Filial Piety of Liangzhou should be inherited and developed further because of its educational function, self-cultivation function and value for more harmonious society. In a way, it's fairly known that translation of the culture is also a feasible and economic way to protect the culture itself. So, Culture Inheritance is one of the foundations for the Chinese-English Translation of the Culture of The Virtue and Filial Piety of Liangzhou.

\subsection{Culture Going-abroad}

Research shows that self-development and closed status couldn't make the culture to survive in the world for ever. Without the comparison and contrast of other cultures, any culture phenomena will be the sole and top one and then finally lose the motivation to develop itself and eventually deteriorate and disappear in the world. Therefore, it's indeed necessary for excellent culture to go abroad so as to be recognized by the foreigners and to enlarge its effect and hence to gain more chance and sites to survive in the world. On the other hand, culture is really the blood and home of a nation. Only if the culture of a nation exists in the world, the nation will continue surviving in the world. And this principle and lesson are the same to the culture of The Virtue and Filial Piety of Liangzhou. Based on the analysis above, it's easy to see that Culture Going-abroad is also one of the research foundations for its translation.

\subsection{Translation Theories}

In a way, Translating Cultures is, in fact, not a traditional term in Translation Studies though some scholars or translators and interpreters have tried to face up to the problem of cultural barriers in their translation study or practice. Of course, Susan Bassnett and Andre Lefevere advocates in their work Translation, History and Culture the hypothesis of the cultural turn. And then, in 1999, David Katan composed the work Translating Cultures: An Introduction for Translators, Interpreters and Mediators. Since then, there occur in translation studies a new term and branch- Translating Culture or Culture Translation. And many Colleges of Foreign Languages set up the Academic Research Scope related to Culture Translation for their postgraduates, such as College of Foreign Languages and Literatures of Northwest Normal University. As to Culture Translation, according to what David Kantan advocates, the most important and first point is that, TRANSLATORS and INTERPRETERS actually act as a Mediator between different cultures in their translation action. As can be seen in his book, David Kanta(2004: 3-4) put forward,

With the continuing globalization of English and the use of computers, the professions will need to change from being seen as inefficient human dictionaries to facilitators for mutual understanding between people. The proposal is for a new role for the traditional translator and interpreter, that of a 'cultural mediator'. 
A basic presupposition is that the organization of experience is not 'reality', but is a simplification and distortion which changes from culture to culture. Each culture acts as a frame within which external signs or 'reality' are interpreted.

Translation itself, following Nida(1976:65), is here viewed as "essentially an aspect of a larger domain, namely, that of communication”. Stein (1975:47) in his aptly titled After Babel takes an even wider view of translation: "inside or between languages, human communication equals translation".

Newmark's(1995) two statements: "translation is the most economical method of explaining one culture's way to another" and "translation mediates cultures" take us back to the main concern of this book: improving communication across cultures.

Based on the analysis above, it's obvious that Culture translation lay emphasis on the core function of translators and interpreters who are to act as mediators between different cultures, and on the other hand the key points of Culture Translation is to improve communication across cultures.

Therefore, in the case of the Chinese-English Translation of the Culture of The Virtue and Filial Piety of Liangzhou, any translators should abide by the rules and principles to guide and conduct his or her translation action and behavior for culture is actually a communication form of people, and languages or signs or voices or any forms reflect culture.

\section{Reasons of Translation Choice}

\subsection{Analysis of Source Text}

As an art form and the culture inheritance, the culture of The Virtue and Filial Piety of course has its scripts which are written in Chinese or recorded in Chinese along with corresponding melody. It's self-evident that its Chinese - English translation should mainly focus on its scripts written in Chinese, and if it's Source Text written in Chinese is so bad that no body likes it for the sake of worse value of text, in my opinion, there's no necessary to translate it into other languages because such text has no practical function to spread in the world. However, in fact, the Source Text of the Culture of The Virtue and Filial Piety indeed has positive and powerful value to be translated. As can be seen in its preface,

The contents of The Virtue and Filial Piety mainly focus on the stories of such people from ancient to modern era as heroes and virtuous men, wise ladies and rigorously chaste, worthy progeny, emperors and generals or officials, gifted scholars and beautiful ladies, and the stories imply praising virtue and punishing vice so as to reflect the society and persuade the people, and its aims of retribution for sin and being filial people are covered in it. Therefore, such culture phenomena are named Virtue and Filial Piety. (Li Wulian \& Feng Tianmin 2011: 7-8)

\subsection{Analysis of the Readers of Target Text}

As to the readers of Target Text of the Culture of The Virtue and Filial Piety, in my opinion, any one who are in English Environment or speak English will read it because it's interesting and valuable for people to be self-cultivated. Even if the circle of readers is narrowed down, the man and woman who has the will and wish to care for their relatives including parents or interested in its research will read through it. And it at least doesn't conclude any contents that are harmful to the sound development of its people or society. Therefore, its translation is bound to appeal to many readers.

\subsection{Consideration of Ideology}

The Culture of The Virtue and Filial Piety, though it necessarily has its inborn defects for it has been inherited from ancient times in China, has been regarded as the treasure of Chinese Culture and listed in The List of National Intangible Cultural Heritages. Therefore, it necessarily labeled the mark of Socialism with Chinese Characteristics. However, whatever it will be and whoever will think whatever it will be, the Culture of The Virtue and Filial Piety of Liangzhou actually aims to construct much better and more harmonious family relationships in society. And whoever and wherever you are, you all have to support your family. And, in a broad sense, no one hopes for worse family relationship for the family is really the basic unit of a society at home or abroad because any individual has to and is born to be one member of a family. On the other hand, with better families, there's better society, and there's much better future for human beings. Hence, based on the analysis above and judging from this perspective, the translation and going-abroad in fact 
doesn't interfere with the ideology of any other countries. On the contrary, it's in fact helpful to construct the community of shared future for mankind.

\section{Translation Strategies}

\subsection{To be "One servant for two masters" or to be "Translator First"}

It's usually said any translator has to be servant for two masters, and one is the source text and another is the target text. However, in my opinion, the Chinese-English translation of the Culture of The Virtue and Filial Piety of Liangzhou should at first abide by the translation strategy of Translator First. In a way, it is the translator who specifically carries out the concrete translation behavior, and he or she knows the requirements of the reader of the target text and the order of the initiator of the translation behavior. If he or she has no comprehensive plan and safeguard of the translation action, what target text will come into being, for the sake of the readers of the target text via abandoning the translation initiator's orders or for the sake of the orders of the translation initiator's via the readers of the target text, and any choice of them will not meet the translation aim of culture inheritance and going-abroad. Therefore, one of the safe and better translation strategies will be Translator first so that he or she can flexibly manage his or her translation so as to make such culture go abroad with Chinese characteristics but adopt to foreigner's taste of appreciation.

\subsection{To be Foreigination or to be domestication}

Lawrence Venuti advocates in 1995 in his work The Translator's Invisibility: A History of Translation the terms of domestication and foreignization. Domestication aims to adapt the message to suit the audience of target text while Foreignization aims to deliberately preserve heterogeneity in the original text so as to break the conventions of the target language. However, first, Culture translation urge the translator to act as mediator between different cultures, second, only to be foreignization or only to be domestication can't face up to and solve the deep and large culture context of the source text. Therefore, the second translation strategy that the Chinese-English translation of the Culture of The Virtue and Filial Piety of Liangzhou should adopt is to flexibly combine domestication with foreignization.

\subsection{To be Alteration Translation or to be Whole Text Translation}

To be whole text translation forces the translator to translate all the materials closely related to the Culture of The Virtue and Filial Piety of Liangzhou even including its melody and player and performance site and instrument while to be alteration translation allows the translator certain freedom to choose and abandon the material even compile parts of the source text material. And judging from the materials being collected, to be whole text translation is in fact not appropriate to the translation of the Culture of The Virtue and Filial Piety of Liangzhou. The reasons are hereafter: first, some contents of the source text have to be abandoned because they embody and reflect the feudalism concepts of the elder for honor and men's being superior to women; second, some sections of the source text publicity the blood and cruel behavior and the haunting of the dead. In my opinion, these materials that covers such phenomena should be banned to translate and spread because people in cotemporary era barely believe there's ghost in the world and should believe that there's no ghost in the world. Therefore, based on the analysis above, the third translation strategy of the Chinese-English Translation of the culture of The Virtue and Filial Piety should be To be Alteration Translation.

\subsection{To be Speech and Informal or to be Paper and Formal}

Because the scripts of the source text are lyrics being sung by the blind, it seems somewhat informal and speech. On the other hand, The Virtue and Filial Piety of Liangzhou is mainly born in and popular in Wuwei Prefecture, it is necessarily influenced by the dialect prevailing in the area. Even if any people in China is hard to understand the dialect being used in Wuwei Prefecture, how could it be that any foreigners can easily and freely read through its target text translated from the source text being written in such dialect. And then, to be paper and formal can not fully reflect its 
feature with Wuwei Dialect. Therefore, in the case of the language being used in target text, it should be carefully singled out so as to adopt the register of the source text.

\subsection{To be Machine Translation or to be Human Translation}

Machine translation is widely used by many translators and translation lines because of its speed and labor-saving feature. However, it's well-known that non-literary materials could be translated through machine translation because its quality of Target Text could be roughly guaranteed, but this experience can't be used in Culture Translation and literary translation because the machine is in fact not understand any thoughts and values embodied in the source text at all. Judging from this perspective, in my opinion, the fourth translation strategy being adopted to translate the Culture of The Virtue and Filial Piety of Liangzhou should be to be Human Translation because human beings could feel from the words and lines of the source text the ideas, thoughts and values of its author.

\subsection{To be Superficial Translation or to be Deep Translation}

To be superficial translation refers to translating the words and phrases and sentences and paragraphs of the source text while to be deep translation refers to translating the thoughts, values, ideas and claims implied and embodied in the words and lines of the source text. As is mentioned above, The virtue and Filial Piety of Liangzhou is in fact an art form and an inheritance of culture. Therefore, to make the foreigners fully understand and acknowledge such culture, the translator should actively use the translation strategy of deep translation to conduct his or her Chinese-English Translation of the Culture of The Virtue and Filial Piety of Laiangzhou.

\subsection{To be Loyalty to Source Text or to be Loyalty to Readers of Target Text}

Source text and Target text are different texts though they are similar to each other because, as Eugene Nida says, there doesn't exist in the world the absolute similarity between the source text and target text. And to be loyalty to readers of target text will promote the translator to sacrifice the original function of the source text while to be loyalty to source text will decrease the cultural infiltration function of the target text. Hence, it's really a dilemma for the translator of such culture. To solve this problem, in my opinion, an important translation strategy that Christiane Nord(2007:

32) advocates is really helpful. She says,

Translation is the production of a functional target text maintaining a relationship with a given source text that is specified according to the intended or demanded function of the target text (translation skopos). Translation allows a communicative act to take place which because of existing linguistic and cultural barriers would not have been possible without it.

According to this view, the translator is committed bilaterally to the source text as well as the target text situation, and is responsible to both the ST sender (or initiator is s/he is also the sender) and the TT receiver. This responsibility is what I call "loyalty". (Christiane Nord 2007:32)

And what Nord advocates can be called briefly as "functionality plus loyalty", that is to say, translator should not only try to keep sound balance of the functionality between the source text and the target text, also be responsibly for both the initiator of the source text and the receiver of the target. In my opinion, what Nord advocates can also be regarded as a translation strategy for it is really useful to guide translator's culture translation behavior. Therefore, Function + loyalty(功能加 忠诚) should also be an effective translation strategy of the Chinese-English Translation of the Culture of The Virtue and Filial Piety of Liangzhou.

\subsection{To be Direct Translation of the material or to be Scientific Administration of Translation Behavior}

To be direct translation of the material means the translator immediately carry out the translation behavior after he/she accepts the source text. Actually, such action has already not adopted by the experienced translation company or group for such translation may produce target text without the sound quality guarantee and then can not be accepted by the TT receiver. Compared to such translation behavior, a responsible and experienced translator with high quality-awareness will "look before you leap". And she/he will make up translation plan and quality-guarantee plan, look up unfamiliar word and read through the source text material again and again. And implementing 
these actions before translation practice is also recognized as indispensible translation strategy in translation line. Due to so many factors, such as culture barrier, dialect barrier etc., to be scientific administration of translation behavior have to be adopted to guide translator's Chinese- English translation of The Culture of The Virtue and Filial Piety of Liangzhou.

\section{Conclusion}

Whether or not The Virtue and Filial Piety of Liangzhou can spread outside Wuwei Prefecture even Hexi Corridor, to be lush and luxuriant and inherited or to be narrow down to Wuwei Prefucture, is obviously up to people's attitude towards it. To protect it of course is not enough while to translate it can not only sustain the culture it embodies, but also enlarge its circle of readers and attract more and more people acknowledge it outside China. And how to effectively carry out the concrete translation action of the Culture of The Virtue and Filial Piety of Lianghzou? Based on all the analysis mentioned above, translator should versatile his or her translation strategy and adopt as many as translation strategies being discussed in this article.

\section{References}

[1] Christiane Nord. 2007.Text Analysis in Translation: Theory, Methodology, and Didactic Application of a Model for Translation-Oriented Text Analysis (Second Edition). Beijing: Foreign Language and Research Press, 32.

[2] Daniel W.L.Lai. 2013. Support and Care for Aging Chinese: A Comparison of Guangzhou, Hong Kong and Taipeii. International Hnadbook of Chinese Family: 290.

[3] David Kanta. 2004. Translating Cultures: An Introduction for Translators, Interpreters and Mediators. Shanghai: Shanghai Foreign Language Education Press, 3-4.

[4] Gunter Senft, Jan-Ola Östman and Jef Verschueren, 2015, Culture and Language Use, Shanghai Foreign Language Education Press, 84.

[5] Katarzyna Pejda. 2016. Self-Cultivation Xiu Shen-Imitation of Personal Model Junzi in Analects. Annals of Arts: 91.

[6] Lee Chung-Duk and Kim II-Myung etc..1998. A Study on the family ethics in 1950s and 1960s through the experiences of the elders. 대만가정학회지: 제36권 11호. :73-74.

[7] Li Wulian \& Feng Tianmin. 2011. The Best Collections of The Virtue and Filial Piety of Liangzhou. Beijing: Culture of China Press, 7-8.

[8] Louise Edwards. 2010. Tranformation of The Woman Warrior Hua Mulan: From Defender of The Family To Servant of The State. Nan Nü: 175.

[9] Shan Lanjing. 2012. Research On the Theory and Practice of the Socialism with Chinese Characteristics. Beijing: Higher Education Press. 75-76.

[10] William Sin. 2013. The Demandingness of Confucianism in the Case of Long-Term Caregiving. Asian Philosophy: 90.

[11] Xi Jinpin. 2017. The Reports of the 19th National Congress of the Communist Party of China. Http: China Daily 2017-`10-25: 59. 